\title{
Multiple and long-term effects of an introduced predatory crab
}

\author{
Catherine E. de Rivera ${ }^{1,2,3, *}$, Edwin D. Grosholz ${ }^{2}$, Gregory M. Ruiz ${ }^{3}$ \\ ${ }^{1}$ Environmental Science and Resources, Portland State University, PO Box 751, Portland, Oregon 97207-0751, USA \\ ${ }^{2}$ Department of Environmental Science and Policy, University of California Davis, One Shields Avenue, Davis, \\ California 95616, USA \\ ${ }^{3}$ Smithsonian Environmental Research Center, PO Box 28, Edgewater, Maryland 21037-0028, USA
}

\begin{abstract}
Despite the importance of invasions, few studies have explored their long-term consequences in marine systems or examined multiple types of population-level effects. Initial effects, however, may not persist over longer time frames; effects have been shown to wane in freshwater systems. We combined 14 yr of field surveys (1993 to 2006) with manipulative experiments to examine the potential for multiple effects of a nonindigenous crab Carcinus maenas on the native shore crab Hemigrapsus oregonensis over time in central California. H. oregonensis abundance was negatively correlated with $C$. maenas abundance. However, $H$. oregonensis abundance rebounded to preinvasion levels once $C$. maenas numbers declined. Other measured changes include a marked decrease in $H$. oregonensis body size and an increase in the proportion of $H$. oregonensis in the high intertidal zone since the arrival of $C$. maenas. These changes in body size and tidal distribution persisted nearly a decade beyond the peak abundance of $C$. maenas and after $H$. oregonensis numbers rebounded. Observed changes in the distribution of the $H$. oregonensis population correspond to shifts in C. maenas abundance, and experiments support a causal relationship. Stepwise regression suggests a complex and possibly nonlinear relationship between predictor variables and $H$. oregonensis size and distribution. Overall, our data indicate strong persistent effects on multiple attributes, with a lag in recovery with declining invader abundance, underscoring the potential for long-term effects that are decoupled from year-to-year invasion dynamics.
\end{abstract}

KEY WORDS: Invasion effect $\cdot$ Nonindigenous species $\cdot$ Carcinus maenas $\cdot$ Demographic response Long-term effects $\cdot$ Body size $\cdot$ Intertidal distribution $\cdot$ Hemigrapsus oregonensis

Resale or republication not permitted without written consent of the publisher

\section{INTRODUCTION}

Nonindigenous species in coastal marine and estuarine systems cause a variety of effects to natural communities and managed habitats (Grosholz 2002). Documented ecological influences include shifts in abundance and habitat use of native species, alteration of habitat structure by ecosystem engineering, changes in community structure, and modification of productivity and nutrient cycling (e.g. Grosholz 2002 and references therein, Castilla et al. 2004, Levin et al. 2006). Coastal invasions also can result in evolutionary effects, such as those documented for morphology and genetic population structure (Geller et al. 2010). Thus, although the implications of most nonindigenous species have not been evaluated (Ruiz et al. 1999), some species exert strong effects that can be expressed in many different ways.

Among the most commonly reported effects of coastal invasions are changes in the abundance or density of resident populations resulting from predation, parasitism, or competition (e.g. Byers 1999, Grosholz et al. 2000, Torchin et al. 2002). Such cases usually highlight significant numerical responses in populations over relatively short time periods and often soon after colonization. However, initial effects 
on population density may not persist over long time frames; effects have been shown to wane in freshwater and terrestrial systems (Strayer et al. 2006). Few marine studies have spanned time horizons that are necessary to assess long-term or persistent effects of biological invasions on recipient communities.

Studies that evaluate more than 1 population-level effect of marine invaders are also rare. An initial literature review found that only $~ 6 \%$ of 57 marine studies on population-level effects examined more than one type of change in a target population (P. W. Fofonoff pers. comm.). Yet, research on predator-prey interactions, whether native or non-native, identifies that population-level responses of prey can include changes in abundance, size, sex ratio, morphology, fecundity, life history, habitat utilization, activity patterns, and other attributes (e.g. Duffy \& Hay 2001, Werner \& Peacor 2003, Snyder \& Evans 2006). The potential for multiple effects may be greatest when predation risk and therefore numerical responses are strong because the benefits of escaping predators are relatively high. For this reason, introduced predators with strong effects on prey populations may be particularly informative in exploring multiple population-level effects.

In our study we tested for multiple changes in a native prey population through time associated with an introduced marine predator. We combined longterm field measurements with laboratory and field experiments to examine whether the introduced European green crab Carcinus maenas (Linnaeus, 1758; henceforth Carcinus) affected the abundance and other attributes of the native shore crab Hemigrapsus oregonensis (Dana, 1851; henceforth Hemigrapsus). A previous study documented that predation by Carcinus greatly decreased the abundance of Hemigrapsus and other native epifauna and infauna in Bodega Harbor within 3 yr (Grosholz et al. 2000). Using a long-term (14 yr) dataset and experiments at this site, we now examined the broader effects of Carcinus on the demography and behavior of the native Hemigrapsus population, testing for changes in Hemigrapsus size, sex ratio, and intertidal distribution coincident with changes in abundance.

We also examined correlations in the abundance of these 2 species with sea-surface temperature (SST), air temperatures, or rainfall. SST can affect larval development rate (e.g. deRivera et al. 2007), year-class success of crabs (Rosenkranz et al. 2001), the abundance and distribution of nearshore crabs (Attrill \& Thomas 1996), and fish and invertebrate community composition (e.g. Collie et al. 2008). Moreover, nearshore temperature fluctuates with upwelling and wind stress, which affect larval delivery (e.g. Roughgarden et al. 1988). Similarly, research has shown lower abundance of Carcinus in the intertidal following cold winters
(Broekhuysen 1937, Beukema 1991). Air temperature can interact with other factors to affect suitability and use of the exposed intertidal zone. Rainfall and subsequent outflow from rivers and streams can affect the salinity of estuarine water, as well as the suitability and use of the intertidal zone. While adult Carcinus frequently utilize subtidal habitats in other ranges, they are often found intertidally and restricted to estuaries along the eastern Pacific, likely due to predation by native Cancer crabs (McDonald et al. 2001, Hunt \& Behrens Yamada 2003); therefore, the environmental conditions of the inter-tidal zone are likely to be especially important in this region.

\section{MATERIALS AND METHODS}

Study site and species. The present study was conducted in the intertidal zone of Gaffney Point, Bodega Harbor, California $\left(38.316^{\circ} \mathrm{N}, 123.054^{\circ} \mathrm{W}\right)$; the site is described in previous studies (Grosholz \& Ruiz 1995, Grosholz et al. 2000). This small $\left(<4 \mathrm{~km}^{2}\right)$ embayment is flushed for the most part each tidal cycle and receives little freshwater input, so Bodega Harbor's salinity mimics the adjacent ocean. The entrance is protected by a jetty; it is a sheltered harbor with predominantly sandy mud substrate.

Carcinus maenas, the European green crab (Decapoda: Portunidae), is a global invader (Carlton \& Cohen 2003) native to the Atlantic coast of Europe (Manning \& Holthuis 1981). The first established population on the Pacific coast was detected in San Francisco Bay in 1989 and rapidly spread north to Bodega Harbor by 1993 (Cohen et al. 1995, Grosholz \& Ruiz 1995). It now inhabits intertidal and shallow subtidal areas from Elkhorn Slough, California, to Queen Cove, British Columbia (Gillespie et al. 2007). While in other regions Carcinus occupies a range of habitats and depths, it is primarily found in sheltered bays and often in the intertidal along the west coast of North America, perhaps in response to predation pressure from crabs of the genus Cancer (McDonald et al. 2001, Hunt \& Behrens Yamada 2003). Carcinus exerts a strong influence on bivalves, crabs, and other native benthic species through predation (Grosholz et al. 2000, Grosholz 2005), and it competes with native decapod crustaceans, shore birds, and other animals with overlapping diets (Elner 1981, Cohen et al. 1995, McDonald et al. 2001). In addition, it can alter community structure through the direct and indirect effects of its intense predation (Leonard et al. 1998).

The habitat, range, and diet of the native shore crab Hemigrapsus oregonensis overlap broadly with those of Carcinus. Hemigrapsus inhabits intertidal, muddy shores from Resurrection Bay, Alaska, USA, to the Gulf 
of California, Mexico (Smith \& Carlton 1975, Jensen 1995). Like Carcinus, Hemigrapsus is euryhaline and omnivorous, though algae likely constitute a larger proportion of their diet (Jensen 1995). Hemigrapsus is smaller than Carcinus: typically adult Hemigrapsus males grow to $49 \mathrm{~mm}$ carapace width (CW) (Jensen 1995), but are typically <30 mm in central California, while Carcinus males grow to $105 \mathrm{~mm}$ along the west coast of the United States (Grosholz \& Ruiz 2003).

Population data. To determine the relative abundance and tidal distribution of crabs over time, we set pitfall traps (20 l polyethylene buckets) at Gaffney Point every year from 1993 to 2006. Three traps were set at $50 \mathrm{~m}$ intervals parallel to the shoreline along each of 4 transects that were $+0.1,+0.4,+0.7$, and $+1.2 \mathrm{~m}$ above mean lower low water (MLLW; $\mathrm{n}=12$ ). The buckets were buried flush with the substrate surface and acted as passive, unbaited traps. Pitfall traps were checked at $\sim 24 \mathrm{~h}$ intervals on 3 consecutive days on spring low tides between 21 May and 14 June each year. We recorded species, gender, and width of dorsal carapace at the widest point for all crabs in the traps. Such traps have been used by many researchers collecting data on relative abundance of mobile organisms (e.g. Kneib 1984, Almeida et al. 2008). While Carcinus can potentially eat Hemigrapsus in the pitfall traps, this type of predation typically results in obvious remains such as limbs and claws, which we did not observe. In addition, the results for the traps have been calibrated with direct counts of crabs conducted with snorkel surveys in this system (Grosholz et al. 2000).

Environmental variables. We explored possible effects of abiotic factors on observed changes in crab populations. We used environmental data collected and archived through the Bodega Oceanographic Observation Node (BOON) to examine possible effects of precipitation and air and sea-surface temperatures on crab numbers, size, and microhabitat use. We examined rainfall (annual mean, minimum, and maximum of monthly totals, and annual total), air temperature (annual mean, standard error, and minimum of mean monthly minima [based on hourly readings] and annual mean, standard error, and maximum of mean monthly maxima), and SST (annual mean, standard error, minimum, and maximum of monthly means of hourly values) for each year (July to June) for each of these 14 measures. We also examined environmental conditions during the $3 \mathrm{~d}$ of trapping, using total $3 \mathrm{~d}$ rainfall, high and low air temperature, and the same 4 SST measures as above, but for averages of hourly readings. SST data were not collected on the $3 \mathrm{~d}$ of trapping in 1999 due to equipment failure, so the missing values for that year were replaced with the mean value for the dataset series.
Laboratory experiments. We conducted 2 experiments to test whether correlations observed could be directly attributable to Carcinus. First, we examined whether Hemigrapsus distribution shifted higher along a slope when Carcinus or the larger native crab Cancer productus were added to aquaria. We also examined whether Carcinus ate more females than males.

Crabs were collected from 24 to $48 \mathrm{~h}$ before each experiment. They were kept with conspecifics in holding tanks and supplied with a continuous flow of filtered seawater from Bodega Harbor. Crabs were fed $24 \mathrm{~h}$ before each experiment; Hemigrapsus were fed crab-food pellets, while Cancer productus and Carcinus were fed pellets and herring.

For the first experiment, we installed a sheet of $6.3 \mathrm{~mm}$ PVC, coated with sand, at an angle in each of two 2081 aquaria, so crabs could distribute themselves along a $1.25 \mathrm{~m}$ long slope from $35 \mathrm{~cm}$ water depth to $5 \mathrm{~cm}$ above the water line. Each aquarium was covered in black plastic, with small flaps we could raise for observations. We used aerated, filtered seawater from Bodega Harbor in the aquaria and exchanged $50 \%$ of the water between each trial. For each aquarium and replicate, we used 30 Hemigrapsus, 15 males and 15 females. Two aquaria were used for each of 5 replicate trials, including 1 experimental and 1 control aquarium. We divided crabs (10 to $30 \mathrm{~mm} \mathrm{CW}$ ) into $5 \mathrm{~mm}$ size groups; each aquarium received the same number per size group. After 3 to $4 \mathrm{~h}$, we tallied the number of Hemigrapsus that were occupying each third (deepest, medium, and shallow plus emergent) of the slope. We then added 2 Carcinus (56 to $75 \mathrm{~mm} \mathrm{CW}$ ) to 1 of the aquaria, switching which one received these predators after each trial for a total of 5 control plus 5 experimental replicates. Three hours later, we again tallied the number of Hemigrapsus along each third of each slope. We repeated the above protocols adding Cancer productus (120 to $136 \mathrm{~mm}$ ) instead of Carcinus as the potential predator in 5 additional control and experimental trials. No cannibalism or density-dependent movements were observed during the laboratory or field studies. However, some Hemigrapsus were eaten, and others managed to squeeze down to the section of the aquarium below the PVC slope. Therefore, we compared the proportion of total remaining Hemigrapsus that occupied the highest third of the slope, the shallow-water plus emergent slope, at the end of the experiment with the proportion that had occupied this highest segment prior to the addition of a predator.

A second aquarium experiment examined whether Carcinus preferentially preyed upon female over male Hemigrapsus. Each aquarium was filled with filtered seawater over a bottom of $4 \mathrm{~cm}$ sand plus 25 clam shells ( 2.5 to $4.0 \mathrm{~cm}$ wide) added for shelter. We added 
10 female Hemigrapsus of 10 to $16 \mathrm{~mm} \mathrm{CW}$, and 10 males matched with female sizes to each of 8 replicate 1131 aquaria. We then recorded predation by 2 Carcinus, 60 to $65 \mathrm{~mm} \mathrm{CW}$, over $5 \mathrm{~h}$.

Data analysis. To examine the intertidal distribution of crabs, pitfall trap data were pooled (combined) across all $3 \mathrm{~d}$ and across all 3 buckets within each transect, yielding 1 value for each transect each year. We used these data to calculate the proportion of Hemigrapsus that were in the highest transect compared to the total catch. All other data analyses, those on abundance patterns, size, and sex ratio, pooled data from all 12 buckets, yielding 1 value $\mathrm{yr}^{-1}(\mathrm{n}=14)$. All data were transformed to meet assumptions of normality. We checked residuals to verify that we were not departing from assumptions of homoscedasticity. For all analyses, we excluded Hemigrapsus recruits $\leq 7 \mathrm{~mm} \mathrm{CW}$ because we did not want the annual variation in recruitment to obscure or overemphasize the potential effects of the independent variables. Hemigrapsus sizes, minus the recruits, ranged from 8 to $40 \mathrm{~mm} \mathrm{CW}$. Excluding recruits never changed the qualitative results. Because crabs grow rapidly during this period, there was a strong positive correlation between Julian Day and the mean Hemigrapsus CW even though all collections occurred within a $3 \mathrm{wk}$ period across the years $\left(\mathrm{r}^{2}=0.46, t=3.21, \mathrm{n}=14, \mathrm{p}=0.008,[\mathrm{CW}]^{1 / 2}=\right.$ $0.023 \times$ day +3.347 ). Therefore, to remove the obvious effects of collection date on size, we used the residuals from Hemigrapsus carapace width versus Julian Day (for the first of the $3 \mathrm{~d}$ of sampling) instead of just CW for all analyses on size.

We performed a principal component analysis (PCA) for parameter reduction of the environmental factors because some combinations of the 21 environmental variables were highly correlated, the number of parameters would exceed the number of replicates if used in a multiple regression, and 21 separate tests for each dependent variable is statistically undesirable. We performed a PCA on 20 of the 21 environmental variables: the $3 \mathrm{~d}$ total rainfall was excluded from the PCA because 12 of its 14 values were zero (but rainfall was $3.0 \mathrm{~cm}$ in 2005 and $0.03 \mathrm{~cm}$ in 2006). Using varimax rotation, 5 components had eigenvalues $>1$. The fifth component, however, explained $<10 \%$ of the variance in the dataset; it only had 1 variable that loaded strongly (>0.75) and had many variables that loaded moderately ( 0.4 to 0.7 ), so it lacked simple structure. The scree plot was not definitive. Because of the lack of interpretability of Component 5 and the low proportion of variance it explained, we selected the top 4 components for extraction. These 4 components captured $77 \%$ of the variation of the original 20 variables, once standardized. Two of the principal components, PC1 and $\mathrm{PC} 2$, represent annual air temperature (PC1: annual mean of mean monthly maxima and minima and minimum of monthly minima; PC2: annual standard error of monthly maxima) and explained 35.9 and $12.3 \%$ of the variance in the data, respectively. PC3 represents annual rainfall (PC3: mean of monthly totals and total and maximum rainfall) and explained 17.2\% of the variance. PC4 was influenced most by the $3 \mathrm{~d}$ sea-surface temperature (PC4: 3 d mean, maximum, and minimum sea-surface temperature) and explained $11.6 \%$ of the variance.

We conducted several analyses to identify which factors may affect the 3 dependent variables (1) squareroot of Hemigrapsus abundance, (2) residual size (from the regression of square-root mean CW vs. Julian Day), and (3) the arcsin[square-root] proportion of the Hemigrapsus that were in the highest transect, using the pooled annual data. To identify if these variables changed over time, we conducted change-point analyses (using Change-Point Analyzer 2.0; Taylor 2000) of the 3 dependent variables versus year. Change-Point Analyzer calculates the cumulative sum for each datapoint (our 1 value $\mathrm{yr}^{-1}$ ), ordered chronologically, by adding the previous sum (starting at zero) to the difference between the current value and the average. A bootstrap analysis, randomly reordering the original values and calculating the cumulative sums for each repeat reordering, then estimates the confidence level that the change really took place. The magnitude of the change, the maximum minus the minimum, of the cumulative sum values for the bootstrap runs is compared to the magnitude of the change of the dataset in its measured, original order to obtain the confidence level estimate. The process is repeated for each side of a change to determine any secondary changes. The change-point analysis included candidate changes that had a $50 \%$ confidence level and identified detected changes that had a $90 \%$ or greater confidence level, using 1000 bootstrap runs without replacement. To examine whether the observed shift in Hemigrapsus spatial distribution was independent of their decrease in size, we also used a multiple regression with both Hemigrapsus size and year as independent variables.

Stepwise multiple regressions examined if the observed changes in the Hemigrapsus dependent variables might be influenced by additional factors. We conducted stepwise regressions because the analyses were of an exploratory nature, aimed at determining the potential importance of environmental factors and predators in explaining the variation in the dependent variables that were seen over time. We used the criteria of $F>3.84$ to add and $F<2.71$ to remove a parameter from these exploratory models. The 4 environmental principal components, Carcinus abundance (sqrt) and the abundance of the third most common crab 
Cancer productus (sqrt) were included as independent factors in the stepwise regressions. We also examined the effect of the environmental principal components and $C$. productus on Carcinus abundance.

We used a paired $t$-test to examine whether Hemigrapsus moved higher after Carcinus or Cancer productus were added to sloped aquaria (temporal comparison). We also tested, with a Student's $t$-test, whether a greater proportion of Hemigrapsus moved to the highest section in aquaria that received Carcinus or C. productus than in aquaria that did not (comparison of predator-addition with control aquaria).

We tested whether the percentage of female Hemigrapsus changed over the 14 yr of the study or with biotic and environmental factors for females $\geq 12 \mathrm{~mm}$ CW, using change-point analysis and stepwise multiple regression, respectively. Almost all Hemigrapsus females are mature at $12 \mathrm{~mm}$ carapace width (authors' unpubl. data). We used the Wilcoxon signed-rank test to identify whether Carcinus preferred females as prey in the aquarium experiment described above.

\section{RESULTS}

\section{Abundance of crabs}

Hemigrapsus oregonensis abundance exhibited a strong negative relationship with Carcinus maenas abundance (Fig. 1; stepwise regression only entered Carcinus abundance: $\mathrm{r}^{2}=0.47, t=-3.29, F_{1,12}=10.83$, $\mathrm{p}=0.006$; the other 5 predictor variables [environmental and $C$. productus] were excluded due to low F-values). Hemigrapsus abundance averaged 244 when there were few Carcinus ( 2 to $27, \mathrm{n}=6 \mathrm{yr}$ ), but just 66.5 when there were many Carcinus (35 to $65, \mathrm{n}=8 \mathrm{yr}$ ). When Carcinus abundance was the dependent variable, none of the predictor variables were retained in the stepwise regression.

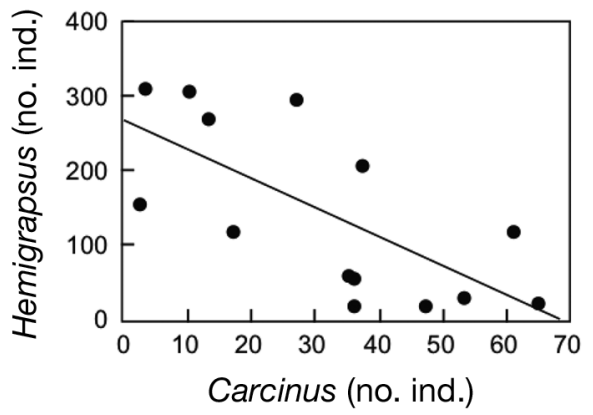

Fig. 1. Hemigrapsus oregonensis, Carcinus maenas. Number of individuals in pitfall traps $(H$. oregonensis versus $C$. maenas) caught in the same traps each year: $\mathrm{r}^{2}=0.48, \mathrm{n}=14$, $y=265.77-3.90 x$
The decline in Hemigrapsus numbers as a function of Carcinus abundance did not translate to a long-term temporal decline, however, likely due to the fluctuating abundance of Carcinus, particularly in recent years (Fig. 2a). Hemigrapsus abundance declined from 308 in 1993 to 19 in 1998, then increased, with the increase detectable by change-point analysis in 2001 (1st level increase from 8.7 to 13.7 crabs [analysis done on square-root-transformed data], $95 \%$ confidence interval: 1997 to 2005, and $94 \%$ confidence that a change occurred, $\mathrm{SD}=4.2$ ). Also detectable in 2001, Carcinus abundance declined (Fig. 2b; change-point analysis 4th level effect from 6.9 to 3.7 crabs [square root]: $95 \%$ confidence interval: 2001 to 2004, confidence level of change $96 \%, \mathrm{SD}=1.5$ ) following their initial increase, detectable in 1994 (change-point analysis 3rd level effect from 0.8 to 6.9 crabs [square root]: $95 \%$ confidence interval: 1994 to 1994, confidence level of change $96 \%, \mathrm{SD}=1.5$ ).

\section{Decrease in size}

Hemigrapsus size decreased over time, despite our exclusion of recruits ( $<7 \mathrm{~mm} \mathrm{CW}$ ) (Fig. 3, Fig. S1 in the supplement at www.int-res.com/articles/suppl/m429 p145_supp.pdf; change-point analysis: detectable in 1999 with confidence interval: 1998 to 2006; 2nd level
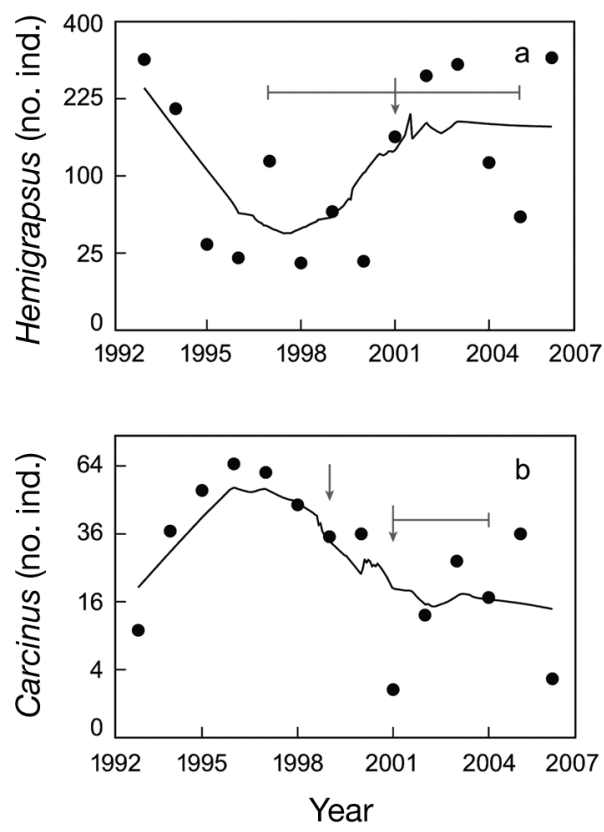

Fig. 2. Hemigrapsus oregonensis, Carcinus maenas. Number of individuals in pitfall traps per year. (a) H. oregonensis, (b) C. maenas. Line generated from a Loess smoothing function using Epanechnikov kernels. The times of change indicated by change-point analysis are shown with grey arrows; the confidence interval for each is shown with a grey error bar 


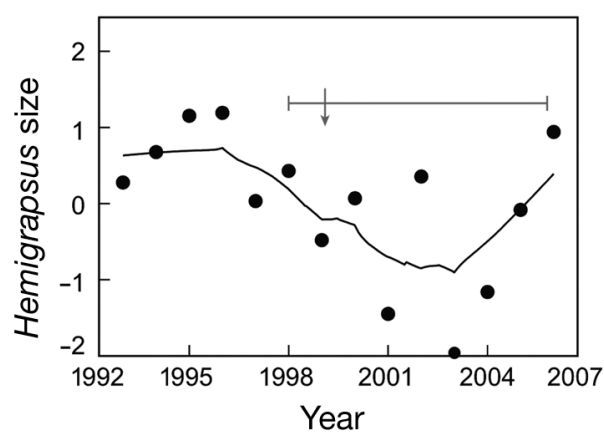

Fig. 3. Hemigrapsus oregonensis. Size (residuals of mean carapace width versus Julian Day) in pitfall traps across years, shown with a Loess smoothing line that used Epanechnikov kernels. The time of change indicated by change-point analysis is shown with a grey arrow; the confidence interval is shown with a grey error bar

change from 0.63 to $0.47 \mathrm{~mm}$ given Julian Day, confidence level $96 \%$, SD $=0.58$ ). Mean carapace width of Hemigrapsus decreased from $14.9 \mathrm{~mm}$ in 1993, when Carcinus first arrived, to $10.8 \mathrm{~mm}$ in 2004, but increased in the last $2 \mathrm{yr}$ of the study. This estimate of the downshift in size is conservative given that we excluded the recruits $(<7 \mathrm{~mm} \mathrm{CW})$ from the analysis. Hemigrapsus size was independent of their abundance $\left(\mathrm{r}^{2}=0.07, t=-0.95, F=0.90, \mathrm{df}=13, \mathrm{p}=0.361\right)$. Stepwise regression examining possible effects of environmental and biotic variables on Hemigrapsus size did not enter any predictor variables.

\section{Changes in distribution and size of crabs across tidal elevation}

The proportion of Hemigrapsus in the highest intertidal transect (+1.2 m MLLW) increased over time, detectable in 2002 (Fig. 4a; change-point analysis: 1st level change from 25 to $51 \%$ crabs (arcsine square root of proportion), $95 \%$ confidence interval: 2001 to 2004, confidence level $96 \%, \mathrm{SD}=0.13$ ). The proportion increased from $2 \%$ in 1993 to $37 \%$ in 2004, then declined back to $11 \%$ in 2006 . This change in tidal height only weakly corresponded to the concurrent decrease in body size $\left(\mathrm{r}^{2}=0.21, t=-1.76, F=3.12, \mathrm{df}=\right.$ $13, \mathrm{p}=0.103)$. In addition, a greater proportion of Hemigrapsus were trapped in the highest transect through time than was expected due to the decrease in mean size alone (multiple regression: adjusted $\mathrm{R}^{2}=$ $0.36, t_{\text {year }}=2.27, \mathrm{p}=0.044, t_{\text {size }}=-0.84, \mathrm{p}=0.420$; whole model $F_{2,11}=4.68, \mathrm{p}=0.034$ ).

Stepwise regression only entered $\mathrm{PC} 3$, with a smaller proportion of Hemigrapsus higher in the intertidal in years with greater PC3 values (Fig. $4 \mathrm{~b} ; \mathrm{r}^{2}=$ $0.34, t=2.49, F_{1,12}=6.21, \mathrm{p}=0.028$, other 5 variables

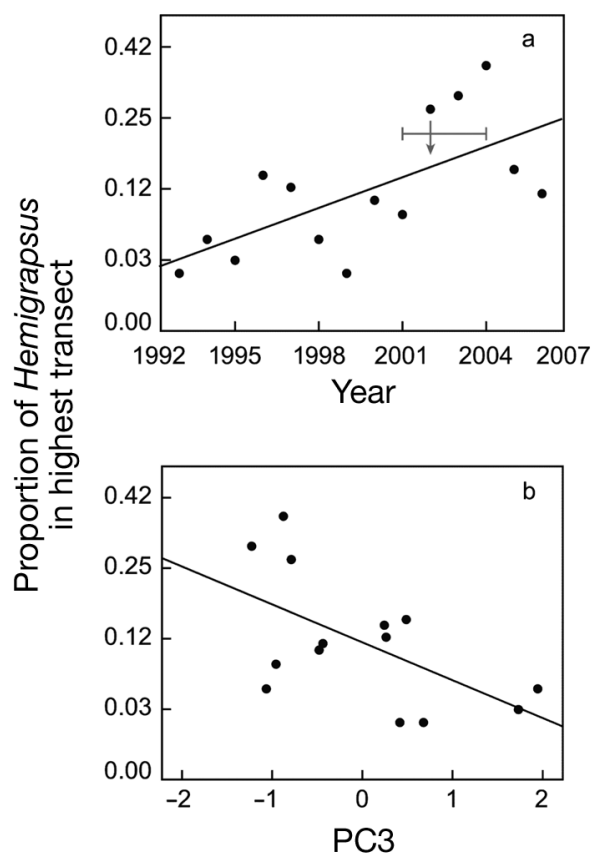

Fig. 4. Hemigrapsus oregonensis. Proportions of H. oregonensis (arcsine square root) in the uppermost transect versus (a) year $\left(r^{2}=0.43, n=14, y=0.025\right.$ Year -50.03$)$ and (b) Principal Component 3 (PC3; mean, maximum, and total annual rainfall; $\left.\mathrm{r}^{2}=0.34, \mathrm{n}=14, y=-0.094 \mathrm{PC} 3+0.341\right)$. Numbers on the $y$-axis are back-transformed to show the proportion of crabs in the highest transect. In Panel a the time of change indicated by change-point analysis is shown with a grey arrow;

the confidence interval is shown with a grey error bar

excluded). The rainfall variables, which contributed strongly to PC3, did not explain this trend, however (Table S1, Fig. S2 in the supplement at www.intres.com/articles/suppl/m429p145_supp.pdf; $\mathrm{r} \ll 0.5$ for each); rather, a much weaker contributor to $\mathrm{PC} 3$, the standard error in annual SST, was negatively correlated with the proportion of Hemigrapsus in the higher intertidal zone (Pearson correlation coefficient $\mathrm{r}=$ $-0.56, p=0.038$; Table S1, Fig. S2).

\section{Change in distribution in sloped aquaria}

In sloped aquaria, an upwards shift in Hemigrapsus distribution was attributable to the presence of Carcinus. More Hemigrapsus used the highest section after Carcinus were added (Fig. 5; $41.0 \pm 10.3 \%$ Hemigrapsus in the highest section, $\mathrm{n}=5$ ) than beforehand $(12.5 \pm 3.0 \%$; paired $t$-test: $t=-3.03, \mathrm{df}=4, \mathrm{p}=0.039)$. In contrast, this difference was not observed in controls $(18.4 \pm 9.5 \%$ after, $22.1 \pm 11.2 \%$ before; $t=0.45, \mathrm{df}=4$, $p=0.676$ ). The redistribution of Hemigrapsus to the highest third of the aquaria was also less pronounced when Cancer productus were added to the sloped 


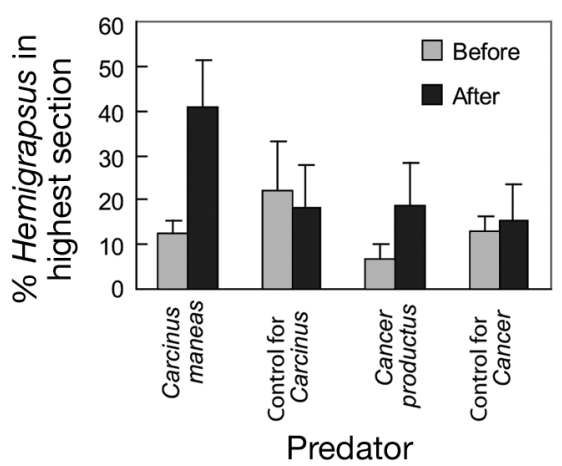

Fig. 5. Hemigrapsus oregonensis. Percent of individuals in the highest section of sloped aquaria before versus after addition of larger, predatory crabs (Carcinus maenas or Cancer productus). Means $\pm 1 \mathrm{SE}$ are shown

aquaria instead of Carcinus (18.9 \pm 9.3\% Hemigrapsus) compared to beforehand $(6.4 \pm 3.5 \%$; paired $t$-test: $t=-2.32, \mathrm{n}=5, \mathrm{p}=0.103 ; C$. productus controls: $15.2 \pm 8.4 \%$ after, $13.0 \pm 3.2 \%$ before; $t=-0.35, \mathrm{df}=4$, $\mathrm{p}=0.742)$.

\section{Sex ratio}

The sex ratio of mature Hemigrapsus in pitfall traps, crabs $\geq 12 \mathrm{~mm} \mathrm{CW}$, did not change over time or with Carcinus abundance (change-point analysis did not detect changes over time at the $90 \%$ confidence level; stepwise regression did not enter any predictor variables). However, Carcinus ate 17 females and 6 males in the preferential predation aquarium experiment, eating more females than males 5 times and more males only once (Wilcoxon signed-rank test: $Z=-1.80$, $\mathrm{n}=8, \mathrm{p}=0.072)$.

\section{Environmental variables}

Of the 4 principal components summarizing the environmental variables, only PC3 (mean maximum and minimum annual rainfall) was retained in the stepwise regression for intertidal distribution, and no PCs were retained in the other stepwise regressions (Fig. 4b). Further exploration with Pearson correlation of potential correlations between environmental and crab variables, however, indicated a positive correlation between PC3 and Carcinus abundance and a negative correlation between PC3 and Hemigrapsus abundance (Table S1, Fig. S2).

Change-point analysis identified a decrease in PC3 detectable in 2000 (1st level from 0.60 to -0.60 , 95\% confidence interval from 1995 to 2002, confidence level $=94 \%, \mathrm{SD}=1.21$ ). Two decreases occurred in PC1 (annual air temperatures), first a decrease in 1998 (1st level from 1.02 to $-1.00,95 \%$ confidence interval from 1998 to 1998, confidence level = 95\%, SD =0.47), then another decrease detectable in 2003 (2nd level from -1.00 to $-0.02,95 \%$ confidence interval from 1999 to 2003, confidence level $=92 \%, \mathrm{SD}=0.47$ ). Change-point analysis did not detect (at the $90 \%$ confidence level) changes over time for the other principal components of the environmental variables.

\section{DISCUSSION}

A population of the native crab Hemigrapsus oregonensis in Bodega Harbor has changed in multiple ways in the 14 yr since the arrival of the non-native crab Carcinus maenas in 1993. The abundance of Hemigrapsus was inversely related to changes in Carcinus numbers, exhibiting an initial strong decline then rebounding in 2001. The fluctuations in Carcinus population size were likely in large part due to variation in recruitment, which recently has been shown for Cancer magister along the NE Pacific to be correlated with wind stress (Shanks \& Roegner 2007, Morgan \& Fisher 2010). Two changes in Hemigrapsus, size and intertidal distribution, lagged behind the increase then decrease in Carcinus numbers and the subsequent numeric recovery of Hemigrapsus. Here, the mean size of Hemigrapsus decreased by nearly two-thirds over time. Size increased in the last 2 yr of the study, perhaps indicating a rebound a decade after Carcinus numbers started to decline. The tidal distribution of Hemigrapsus also shifted dramatically. Between 1993 and 2004, a proportion of Hemigrapsus, 18.5 times higher than in 1993, shifted to the highest intertidal zone. While size partitioning across the intertidal occurs in other nearshore crabs (e.g. Orth \& van Montfrans 1987, Dumbauld et al. 1993, McMillan et al. 1995) and weakly here, the upward habitat shift was much greater than expected solely from the concurrent decrease in Hemigrapsus size.

Three types of factors, as well as their interactions, potentially influenced the shift in population size, body size, and intertidal distribution of Hemigrapsus: (1) environmental factors, (2) risk of predation by green crabs, and (3) risk of predation by other predators such as Cancer productus. Given the findings on the effect of wind stress on the recruitment of other larval crabs, we expect that wind stress likely affects recruitment of both these crab species (Shanks \& Roegner's 2007, Morgan \& Fisher 2010). Other environmental factors may be important as well. Annual rainfall (PC3) was correlated with higher Carcinus abundance and lower Hemigrapsus abundance. Rainfall and Carcinus abun- 
dance may both play important, perhaps interactive, roles in Hemigrapsus populations. Rainfall could affect recruitment of these crabs, the distribution of predators, or the amount of algae available as a food resource to Hemigrapsus. Our data, however, are consistent with Carcinus being a key driver of the change in Hemigrapsus. The correlation with rainfall was not as strong as the correlation between the crab abundances, and it was not retained in statistical models that examined both variables simultaneously.

Similarly, our data best support the hypothesis that predation risk by Carcinus influenced Hemigrapsus intertidal habitat use, but that intertidal use also may be affected by the variation in SST. There was a clear shift to higher areas in aquaria as a clear response to predation risk by Carcinus. Hemigrapsus always shifted their distribution to a higher position when Carcinus were added to aquaria, but they did not shift in control aquaria or as strongly when the native species Cancer productus was added. Carcinus and Cancer productus remained in deeper water with only brief forays to mid-elevations. C. productus eat Hemigrapsus, but not as frequently as do Carcinus (authors' unpubl. data). Our field measurements and opportunistic observations revealed a large, though variable, number of Carcinus, many fewer C. productus, and a dearth of other significant crab predators such as predatory fish or birds.

Upward shifts may also be influenced by the tradeoffs and interactions between predation risk in the lower intertidal zone, especially in years with many large Carcinus, and variably stressful environmental conditions higher in the intertidal or greater recruitment. However, the importance and meaning of the correlations we found between the environmental variables and the distribution of Hemigrapsus through the intertidal are unclear. The third principal component was negatively correlated with higher intertidal use and abundance of Hemigrapsus. However, the factors that loaded heavily on PC3 (rainfall factors) had low correlation with use of the upper intertidal and instead were more highly correlated with the abundance of Hemigrapsus (negatively) and of Carcinus (positively).

Rainfall could affect the abundance of crabs in the intertidal indirectly due to weather conditions affecting their recruitment or the distribution of predators, and thus may be connected indirectly to the decreased abundance and use in the upper intertidal of Hemigrapsus. The proportion of Hemigrapsus in the intertidal was also correlated with the standard error of SST, both negatively with the annual standard error and positively with the $3 \mathrm{~d}$ standard error. The variability in SST may reflect more frequent changes in upwelling, which has been shown to affect recruitment levels in other species (Roughgarden et al. 1988, Connolly et al. 2001). As the pattern of intertidal use was correlated with size, despite our exclusion in data analysis of the smallest crabs, weather and upwelling patterns affecting recruitment and therefore proportion of the population that were young of the year may directly affect the proportion in the upper intertidal.

While Carcinus abundance was not retained in models examining potential drivers of the observed decrease in size or microhabitat shift of Hemigrapsus, a strong linear relationship with predator abundance would not be predicted if there were a functional or other non-linear response, trait-mediated effects (i.e. behavioral compensation of prey to reduce predation risk), or a time-lagged response (e.g. Sarnelle 2003). For example, if Hemigrapsus move higher in the intertidal to seek a potential shallow-water refuge when they encounter aquatic predators and encounters are independent of density because Carcinus move more when they are at low densities, the proportion of Hemigrapsus using the highest transect would not correlate with Carcinus density.

The effects of nonindigenous species can vary in both space and time, and relatively little information is currently available for either dimension in marine systems (Ruiz et al. 1999). For freshwater systems, Strayer et al. (2006) and Strayer \& Malcom (2007) suggest that (1) using short-term data on strong initial effects to predict the long-term effects of biological invasions can exaggerate some potential consequences, which are likely to be modulated over time, and (2) long-term studies may reveal more nuanced effects of invasions on native species that develop over time. Our analysis provides further support for this perspective, demonstrating both of these outcomes for a marine invasion.

The observed changes in Hemigrapsus body size and habitat use illustrate potentially chronic repercussions of predation by an invader and demonstrate the importance of long-term studies of invasion. Such effects may alter the dynamics of native species when faced with additional perturbations. A multi-year decline in body size could reduce the reproductive potential of the population, as with other crabs and fishes (e.g. Prager et al. 1990, Hines 1991, Berkeley et al. 2004). The shift to higher tidal areas inevitably would have decreased their potential foraging time: because of the inherent longer exposure time, individual Hemigrapsus higher in the intertidal must spend more time under the shelter of rocks to prevent desiccation or predation by shorebirds. Therefore, both responses could decrease the likelihood that an affected organism attains numeric or demographic recovery initially or after future predation pressure, especially for populations that are less likely to be supplied from external larval sources. Similar to other studies, especially those 
in aquatic systems, the non-lethal consequences of the behavioral changes that result from the threat of predation may be as or even more important than the direct consequences of predation to the population (Peacor \& Werner 2001, Preisser et al. 2005).

Previous studies on the effect of temperature on biological invasions suggest that some non-native species will be favored by climate change. Climate change may increase the ranges of species in recipient regions (Dukes \& Mooney 1999) and may bring them an advantage locally over natives due to different thermal tolerances (Sorte et al. 2010), earlier and higher recruitment under warmer conditions (Stachowicz et al. 2002), or increased reproductive rates or survivorship (Walther et al. 2009). Similarly, the data here suggest changing climate may serve as a perturbation that interacts with invasion by non-native predators and may mediate the extent or speed of recovery. The abundance of both crabs and the size and habitat use of the native Hemigrapsus crabs were correlated with different environmental conditions likely to change due to increases in atmospheric carbon dioxide (Meehl et al. 2007). For example, increased minimum air temperature was correlated with an increased abundance of the non-native crab. Similarly, increased rainfall was correlated positively with the abundance of non-native Carcinus and negatively with the native Hemigrapsus, and variability in SST was correlated with an increase in the proportion of Hemigrapsus using higher intertidal areas. Therefore, warmer or more variable temperatures could increase the success of an invading population as well as extend or exacerbate the longer term repercussions of its predation on native crabs.

Additional examples from terrestrial and freshwater systems demonstrate how non-native species can affect the distribution, habitat displacement, and other behaviors of native species. Such changes have been reported for a variety of non-native arthropods and fishes (Fraser \& Gilliam 1992, Gotelli \& Arnett 2000, and reviewed by Snyder \& Evans 2006). Similarly, studies show that nonindigenous species have had strong effects on the size-frequency distribution, growth rates, and even morphology of natives, often along with other effects (Fraser \& Gilliam 1992, Mills et al. 2004, Carroll et al. 2005, Light 2005). Studies of invasions have identified multiple changes to community structure and ecosystem processes as well (Crooks 2001, Levine et al. 2003). For example, Neira et al. (2006) identified physiochemical changes to the habitat due to invasion by hybrid Spartina that, in turn, affected the benthic community's species composition and food web structure.

Not only have multiple types of effects been demonstrated on species and community levels, research in other systems is arising that identifies how these effects last well beyond the initial changes to a recipient community. Changes to the seed bank (Lonsdale et al. 1988, Holmes \& Cowling 1997, Drake 1998), soil nutrients (D'Antonio \& Vitousek 1992, Corbin \& D'Antonio 2004 and references therein), and soil mycorrhizae (Batten et al. 2006, Mummey \& Rillig 2006) all have had long-term effects on the population dynamics of native plant populations. The effects of fire ants have not diminished in the decades since their invasion (Gotelli \& Arnett 2000). In freshwater systems, population size, recruitment, and growth of native freshwater mussels all stabilized or increased a decade after the zebra mussel invasion, but these measures have not rebounded to pre-invasion levels, and the body condition measure of native mussels remains low (Strayer \& Malcom 2007).

In this study we observed changes in abundance, size, and distribution of the native crab Hemigrapsus that were evident across a decade. These shifts in the native crab population coincide with the appearance and increase of an invader, and they likely result from increased predation pressure on the native crab. The last 2 yr of the dataset may suggest a recent possible rebound towards pre-invasion states. Hemigrapsus, which has pelagic larvae and could have recruited from other less affected populations, showed rapid numeric recovery when Carcinus numbers decreased. The Carcinus range only extends south to Elkhorn Slough off Monterey Bay and, though in the center of the range, is at very low numbers from just north of Bodega Bay, California, through Vancouver Island, British Columbia, whereas Hemigrapsus populations are in high density north and south of the population examined here (authors' unpubl. data). The Hemigrapsus population also has increased recently in body size to its original mean and exhibited a partial return to its pre-invasion habitat distribution. Because there were fluctuations throughout, it is premature to say that the 2 data points toward the end of the observation period reflect recovery.

Despite the range of effects that can occur from biological invasions in all systems, analyses of persistence or multiple effects in marine systems are largely lacking. Most studies are limited in scope, both in terms of timeframes and of potential interactions (Ruiz et al. 1999). Only now are broader and long-term studies beginning to emerge, both in marine systems (present study, and for community and habitat changes Crooks 2001, Neira et al. 2005, 2006) and freshwater systems (Strayer et al. 2006, Strayer \& Malcom 2007). These long-term studies reveal interesting nuances and trends not identifiable from the shorter ones.

The results of the present study broadly imply that predators could yield sustained effects on prey that affect the structure of communities that are newly 
organized due to climate change-related range shifts or invasion or could change the timing and extent of oscillations in population size of predators and prey. Newly colonizing generalist predators could cause sustained population-level effects in resident prey that cause additional stress and decreased reproductive output of prey populations. When prey species are the colonizers due to climate change or other forces, they may not be prevented by predators from establishing self-sustaining populations. This could greatly limit or delay natural spread upstream in response to warming water and limit the number of habitats colonized relative to those with suitable abiotic conditions and within the dispersal range.

Acknowledgements. We thank B. Agius, C. Dean, R. Estelle, C. Juhasz, N. Rayl, L. Rodriguez, K. Shirley, C. Sorte, R. Tinsman, and B. Williams for their hours of help in the field and laboratory. The field work was conducted at the Bodega Marine Reserve. We also acknowledge grants from the National Science Foundation (E.D.G., G.M.R.), Sea Grant/ NOAA Partnership Program (E.D.G.), California Sea Grant (E.D.G.), and the Pacific States Marine Fisheries Commission (C.E.D., E.D.G., and G.M.R.).

\section{LITERATURE CITED}

Almeida MJ, Flores AAV, Queiroga H (2008) Effect of crab size and habitat type on the locomotory activity of juvenile shore crabs, Carcinus maenas. Estuar Coast Shelf Sci 80:509-516

Attrill MJ, Thomas RM (1996) Long-term distribution patterns of mobile estuarine invertebrates (Ctenophora, Cnidaria, Crustacea: Decapoda) in relation to hydrological parameters. Mar Ecol Prog Ser 143:25-36

Batten KM, Scow KM, Davies KF, Harrison SP (2006) Two invasive plants alter soil microbial community composition in serpentine grasslands. Biol Invasions 8:217-230

Berkeley SA, Chapman C, Sogard SM (2004) Maternal age as a determinant of larval growth and survival in a marine fish, Sebastes melanops. Ecology 85:1258-1264

Beukema JJ (1991) The abundance of shore crabs Carcinus maenas (L.) on a tidal flat in the Wadden Sea after cold and mild winters. J Exp Mar Biol Ecol 153:97-113

Broekhuysen GJ Jr (1937) On development, growth and distribution of Carcinides maenas (L.). Arch Neerl Zool 2: 257-399

Byers JE (1999) The distribution of an introduced mollusc and its role in the long-term demise of a native confamilial species. Biol Invasions 1:339-353

> Carlton JT, Cohen AN (2003) Episodic global dispersal in shallow water marine organisms: the case history of the European shore crabs Carcinus maenas and C. aestuarii. J Biogeogr 30:1809-1820

Carroll SP, Loye JR, Dingle H (2005) And the beak shall inherit-evolution in response to invasion. Ecol Lett 8: 944-951

Castilla JC, Lagos NA, Cerda M (2004) Marine ecosystem engineering by the alien ascidian Pyura praeputialis on a mid-intertidal rocky shore. PSZNI: Mar Ecol 268: $119-130$

Cohen AN, Carlton JT, Fountain MC (1995) Introduction, dispersal and potential impacts of the green crab Carcinus maenas in San Francisco Bay, California. Mar Biol 122: $225-237$

Collie JS, Wood AD, Jeffries HP (2008) Long-term shifts in the species composition of a coastal fish community. Can J Fish Aquat Sci 65:1352-1365

Connolly SR, Menge BA, Roughgarden J (2001) A latitudinal gradient in recruitment of intertidal invertebrates in the northeast Pacific Ocean. Ecology 82:1799-1813

Corbin JD, D'Antonio CM (2004) Effects of exotic species on soil nitrogen cycling: implications for restoration. Weed Technol 18:1464-1467

Crooks JA (2001) Assessing invader roles within changing ecosystems: historical and experimental perspectives on an exotic mussel in an urbanized lagoon. Biol Invasions 3:23-36

D'Antonio CM, Vitousek PM (1992) Biological invasion by exotic grasses, the grass fire cycle, and global change. Annu Rev Ecol Evol Syst 23:63-87

deRivera CE, Ruiz GM, Hitchcock NG, Teck SA, Steves B, Hines AH (2007) Larval development rate predicts range expansion of an introduced crab. Mar Biol 150:1275-1288

$>$ Drake DR (1998) Relationships among the seed rain, seed bank and vegetation of a Hawaiian forest. J Veg Sci 9: $103-112$

Duffy JE, Hay ME (2001) The ecology and evolution of marine consumer-prey interactions. In: Bertness MD, Gaines SD, Hay ME (eds) Marine community ecology. Sinauer, Sunderland, MA, p 131-157

> Dukes JS, Mooney HA (1999) Does global change increase the success of biological invaders? Trends Ecol Evol 14: $135-139$

$>$ Dumbauld BR, Armstrong DA, McDonald TL (1993) Use of oyster shell to enhance intertidal habitat and mitigate loss of Dungeness crab (Cancer magister) caused by dredging. Can J Fish Aquat Sci 50:381-390

Elner RW (1981) Diet of green crab Carcinus maenas (L.) from Port Hebert, southwestern Nova Scotia. J Shellfish Res 1:89-94

> Fraser DF, Gilliam JF (1992) Nonlethal impacts of predator invasion: facultative suppression of growth and reproduction. Ecology 73:959-970

Geller JBB, Darling JA, Carlton JT (2010) Genetic perspectives on marine biological invasions. Annu Rev Mar Sci 2:367-393

Gillespie GE, Phillips AC, Paltzat DL, Therriault TW (2007) Status of the European green crab, Carcinus maenas, in British Columbia - 2006. Can Tech Rep Fish Aquat Sci 2700:vii + $39 \mathrm{p}$

Gotelli NJ, Arnett AE (2000) Biogeographic effects of red fire ant invasion. Ecol Lett 3:257-261

Grosholz ED (2002) Ecological and evolutionary consequences of coastal invasions. Trends Ecol Evol 17:22-27

Grosholz ED (2005) Recent biological invasion may hasten invasional meltdown by accelerating historical introductions. Proc Natl Acad Sci USA 102:1088-1091

Grosholz ED, Ruiz GM (1995) Spread and potential impact of the recently introduced European green crab, Carcinus maenas, in central California. Mar Biol 122:239-247

Grosholz ED, Ruiz GM (2003) Biological invasions drive size increases in marine and estuarine invertebrates. Ecol Lett 6:700-705

Grosholz ED, Ruiz GM, Dean CA, Shirley KA, Maron JL, Connors PG (2000) The impacts of a nonindigenous marine predator in a California bay. Ecology 81:1206-1224

Hines AH (1991) Fecundity and reproductive output in nine species of Cancer crabs (Crustacea, Brachyura, Cancridae). Can J Fish Aquat Sci 48:267-275 
Holmes PM, Cowling RM (1997) Diversity, composition and guild structure relationships between soil-stored seed banks and mature vegetation in alien plant-invaded South African fynbos shrublands. Plant Ecol 133:107-122

> Hunt CE, Behrens Yamada S (2003) Biotic resistance experienced by an invasive crustacean in a temperate estuary. Biol Invasions 5:33-43

Jensen GC (1995) Pacific Coast crabs and shrimps. Sea Challengers. Monterey, CA

Kneib RT (1984) Patterns of invertebrate distribution and abundance in the intertidal salt marsh: causes and questions. Estuaries 7:392-412

Leonard GH, Levine JM, Schmidt PR, Bertness MD (1998) Flow-driven variation in community structure in a Maine estuary. Ecology 79:1395-1411

Levin LA, Neira C, Grosholz ED (2006) Invasive cordgrass modifies wetland trophic function. Ecology 87:419-432

> Levine JM, Vilà M, D'Antonio CM, Dukes JS, Grigulis K, Lavorel S (2003) Mechanisms underlying the impacts of exotic plant invasions. Proc Biol Sci 270:775-781

Light T (2005) Behavioral effects of invaders: alien crayfish and native sculpin in a California stream. Biol Invasions 7:353-367

Lonsdale WM, Harley K, Gillett JD (1988) Seed bank dynamics in Mimosa pigra, an invasive tropical shrub. J Appl Ecol 25:963-976

Manning RB, Holthuis LB (1981) West African brachyuran crabs (Crustacea: Decapoda). Smithson Contrib Zool 306: 1-379

McDonald PS, Jensen GC, Armstrong DA (2001) The competitive and predatory impacts of the nonindigenous crab Carcinus maenas (L.) on early benthic phase Dungeness crab Cancer magister Dana. J Exp Mar Biol Ecol 258: 39-54

McMillan RO, Armstrong DA, Dinnel PA (1995) Comparison of intertidal habitat use and growth rates of two northern Puget Sound cohorts of 0+ age Dungeness crab, Cancer magister. Estuaries 18:390-398

Meehl GA, Stocker TF, Collins WD, Friedlingstein P and others (2007) Global climate projections. In: Solomon S, Qin D, Manning M, Chen Z and others (eds) Climate change 2007: The physical science basis. Contribution of Working Group I to the Fourth Assessment Report of the Intergovernmental Panel on Climate Change. Cambridge University Press, Cambridge, p 749-845

Mills MD, Rader RB, Belk MC (2004) Complex interactions between native and invasive fish: the simultaneous effects of multiple negative interactions. Oecologia 141:713-721

Morgan SG, Fisher JL (2010) Larval behavior regulates nearshore retention and offshore migration in an upwelling shadow and along the open coast. Mar Ecol Prog Ser 404:109-126

Mummey DL, Rillig MC (2006) The invasive plant species Centaurea maculosa alters arbuscular mycorrhizal fungal communities in the field. Plant Soil 288:81-90

Neira C, Levin LA, Grosholz ED (2005) Benthic macrofaunal communities of three sites in San Francisco Bay invaded by hybrid Spartina, with comparison to uninvaded habitats. Mar Ecol Prog Ser 292:111-126

Neira C, Grosholz ED, Levin LA, Blake R (2006) Mechanisms generating modification of benthos following tidal flat

Editorial responsibility: Romuald Lipcius,

Gloucester Point, Virginia, USA invasion by a Spartina hybrid. Ecol Appl 16:1391-1404

Orth RJ, van Montfrans J (1987) Utilization of a seagrass meadow and tidal marsh creek by blue crabs Callinectes sapidus. I. Seasonal and annual variations in abundance with emphasis on post-settlement juveniles. Mar Ecol Prog Ser 41:283-294

> Peacor SD, Werner EE (2001) The contribution of traitmediated indirect effects to the net effects of a predator. Proc Natl Acad Sci USA 98:3904-3908

Prager MH, McConaugha JR, Jones CM, Geer PJ (1990) Fecundity of blue crab, Callinectes sapidus, in Chesapeake Bay: biological, statistical and management considerations. Bull Mar Sci 46:170-179

Preisser EL, Bolnick DI, Benard MF (2005) Scared to death? The effects of intimidation and consumption in predatorprey interactions. Ecology 86:501-509

Rosenkranz GE, Tyler AV, Kruse GH (2001) Effects of water temperature and wind on year-class success of Tanner crabs in Bristol Bay, Alaska. Fish Oceanogr 10:1-12

> Roughgarden J, Gaines S, Possingham H (1988) Recruitment dynamics in complex life cycles. Science 241:1460-1466

Ruiz GM, Fofonoff P, Hines AH, Grosholz ED (1999) Nonindigenous species as stressors in estuarine and marine communities: assessing invasion impacts and interactions. Limnol Oceanogr 44:950-972

Sarnelle O (2003) Nonlinear effects of an aquatic consumer: causes and consequences. Am Nat 161:478-496

Shanks AL, Roegner GC (2007) Recruitment limitation in Dungeness crab populations is driven by variation in atmospheric forcing. Ecology 88:1726-1737

Smith RI, Carlton JT (eds) (1975) Light's manual: intertidal invertebrates of the central California coast, 3rd edn. University of California Press, Berkeley, CA

$>$ Snyder WE, Evans EW (2006) Ecological effects of invasive arthropod generalist predators. Annu Rev Ecol Evol Syst 37:95-122

Sorte CJB, Williams SL, Zerebecki RA (2010) Ocean warming increases threat of invasive species in a marine fouling community. Ecology 91:2198-2204

Stachowicz JJ, Terwin JR, Whitlatch RB, Osman RW (2002) Linking climate change and biological invasions: ocean warming facilitates nonindigenous species invasions. Proc Natl Acad Sci USA 99:15497-15500

Strayer DL, Malcom HM (2007) Effects of zebra mussels (Dreissena polymorpha) on native bivalves: The beginning of the end or the end of the beginning? J N Am Benthol Soc 26:111-122

Strayer DL, Eviner VT, Jeschke JM, Pace ML (2006) Understanding the long-term effects of species invasions. Trends Ecol Evol 21:645-651

Taylor WA (2000) Change-point analysis: a powerful new tool for detecting changes. Available at: www.variation.com/ $\mathrm{cpa} /$ tech/changepoint.html (accessed Sep 2009)

Torchin ME, Lafferty KD, Kuris AM (2002) Parasites and marine invasions. Parasitology 124:S137-S151

Walther GR, Roques A, Hulme P, Sykes M and others (2009) Alien species in a warmer world: risks and opportunities. Trends Ecol Evol 24:686-693

> Werner EE, Peacor SD (2003) A review of trait-mediated indirect interactions in ecological communities. Ecology 84: 1083-1100

Submitted: September 19, 2007; Accepted: February 22, 2011 Proofs received from author(s): May 9, 2011 